\title{
Transcriptional regulators of Arabidopsis secondary cell wall formation: tools to re-program and improve cell wall traits
}

\author{
Rakesh Bhatia and Maurice Bosch* \\ Institute of Biological, Environmental and Rural Sciences, Aberystwyth University, Aberystwyth, UK \\ Correspondence:mub@aber.ac.uk \\ Edited by: \\ James Lloyd, Stellenbosch University, South Africa \\ Reviewed by: \\ Rachel Burton, University of Adelaide, Australia \\ Javier Sampedro, University of Santiago de Compostela, Spain
}

Keywords: secondary cell wall, transcription factors, Arabidopsis, lignin, recalcitrance, lignocellulosic biomass, genetic engineering, biofuels

\section{A commentary on}

Identification of novel transcription factors regulating secondary cell wall formation in Arabidopsis

by Cassan-Wang, H., Goué. N., Saidi, M. N., Legay, S., Sivadon, P., Goffner, D., et al. (2013). Front. Plant Sci. 4:189. doi: 10.3389/fpls.2013.00189

Secondary cell walls (SCWs) comprise the main portion of plant biomass and represent an abundant renewable resource of polysaccharides for conversion into sugars and subsequent fermentation to liquid biofuels. An upswing in lignocellulosic biomass-derived biofuels, including from grass and woody energy crops and agricultural residues, offers significant environmental and socio-economic benefits over the use of dwindling and polluting non-renewable fossil fuels. A key challenge for realizing commercial biofuel production resides in the economically unfeasible sugar yields after enzymatic hydrolysis of lignocellulosic biomass. This low saccharification efficiency is caused by the recalcitrant nature of the cell wall owing to the crystallinity of cellulose and interactions between the polysaccharides and lignin polymers within the cell wall matrix (Himmel et al., 2007; Demartini et al., 2013). Overcoming biomass recalcitrance has generally been tackled with costly and energy intensive pre-treatments, which so far have met bioconversion requirements with limited success. One alternative path to optimize the digestibility of lignocellulose for sustainable biofuel production is the genetic manipulation of SCW characteristics via transcription factors (TFs), powerful tools to orchestrate the biosynthesis and deposition of the main SCW components cellulose, lignin, and hemicellulose.

Research efforts have revealed an extensive, complex and hierarchical regulatory network of SCW-related TFs predominantly comprising NAC and MYB family members in Arabidopsis (Handakumbura and Hazen, 2012; Hussey et al., 2013). Delineating the topology and dynamics of this regulatory network will require exploring its nodes, hubs, and edges. Cassan-Wang et al. (2013) confront these fundamental goals by tallying new TFs to the network regulating SCW formation in Arabidopsis. Their innovative strategy to identify transcriptional regulators involved the exploitation of several Arabidopsis SCW-related transcriptome datasets combined with in silico expression and histology-based phenotyping screens. Since lignin is commonly acknowledged to inhibit biomass digestibility, their systematic approach proved useful as six TDNA lines from candidate TFs revealed altered lignin deposition profiles; including hyper- and hypo-lignification as well as ectopic lignin deposition (Cassan-Wang et al., 2013). Co-expression analysis suggests that some of these TFs not only play a role in lignin biosynthesis, but also regulate other parts of the SCW formation program including cellulose and xylan biosynthesis. It is noteworthy that the majority of T-DNA/RNAi lines corresponding to candidate SCW-related TFs did not reveal a lignin phenotype. The fact that their candidate list of TFs contains known SCW regulators validates the robustness of their identification strategy. However, it is well established that redundancy exists among TFs and the authors, therefore, rightly touch upon the need for analyzing over-expressor lines and/or multiple gene knock-out mutants of homologous TFs in order to increase the likelihood of a detectable SCW phenotype and understanding of gene function. One approach that has been particularly successful in addressing this problem of functional redundancy is that of dominant repression (Hiratsu et al., 2003). The expression of chimeric repressors (specific TF fused to a repression domain) induces loss-of-function phenotypes in transgenic plants by dominating the activity of both endogenous and functionally redundant TFs, facilitating the analysis of TF function in SCW formation (Zhong et al., 2007; McCarthy et al., 2009). The identification of the lignin mutants by Cassan-Wang et al. (2013) was ultimately based on histological observations and more extensive compositional analysis might increase the number of SCW-related mutants beyond the six already identified. For instance, it is known that certain SCW-related TFs regulate specific lignin monomers (Zhao et al., 2010; Öhman et al., 2013). The ratios of these monomers may therefore have been shifted in some TF mutants, without causing an obvious phenotype for plant growth or lignin staining but potentially affecting recalcitrance and saccharification yield. 
The list of potential SCW-related TFs identified by Cassan-Wang et al. (2013) highlights the expanding complexity of SCW regulation, including involvement of TF families for which participation in SCW regulation is not yet well established. This encompasses members from the AP2/ERF and Aux/IAA TF-families, also identified in other screens targeted at genes involved in SCW formation (Bosch et al., 2011; Hirano et al., 2013). Involvement of these families in the regulatory SCW network suggests the participation of complex ethylene- and auxin-signaling pathways. In particular AP2/ERF TFs represent attractive targets for genetic engineering to enhance crop performance in terms of stress tolerance or higher yield as well as SCW properties for bioconversion purposes (Ambavaram et al., 2011; Vahala et al., 2013).

Although TFs provide attractive targets for altering complex cell wall traits, the intricacy of regulatory networks and their integration with different metabolic and signaling pathways, means that changing the levels of a certain TF can result in pleiotropic effects. In accordance, CassanWang et al. (2013) observed delayed flowering in their hyperlignified $h b 5$ line and earlier flowering in the hypolignified blh6 and zinc finger lines. This corroborates previous reports that some TFs of the SCW thickening and xylem formation program are coupled with the flowering induction program (Melzer et al., 2008; Sibout et al., 2008; Xu et al., 2012), exemplifying the danger of unintended consequences when altering SCW synthesis due to its tight integration with other developmental processes.

As eudicots and monocot grasses exhibit differences in cell wall composition and architecture as well as morphological and anatomical distinctions (Vogel, 2008; Sarkar et al., 2009), one could argue that they may have evolved a unique transcriptional regulatory network controlling SCW biosynthesis. Interestingly, phylogenetic and co-expression analysis illustrate evolutionary conservation of the transcriptional regulators in SCW biosynthesis (Ruprecht et al., 2011; Zhong et al., 2011). Discovering SCW-related TFs in the model system Arabidopsis should therefore provide compatible tools for the engineering of woody and grass energy crops alike. Indeed, researchers developing switchgrass as a dedicated bioenergy feedstock have exploited this apparent conservation; over-expression of the MYB TF PvMYB4, an orthologue of Arabidopsis AtMYB4, results in repression of genes involved in lignin biosynthesis, leading to reduced cell wall recalcitrance and a more than doubling of the bioethanol yield (Shen et al., 2013). This and other examples clearly indicate the potential of translating results from Arabidopsis to tailor the biochemistry of SCWs in lignocellulosic feedstocks for improved performance. An important consideration is the trade-off between reduced cell wall recalcitrance and biomass yield, often encountered in genetic engineering efforts aimed at modifying SCWs. New synthetic biology approaches may alleviate such growth penalties. This is illustrated by a study in which SCW biosynthesis and TF genes were used to re-program the spatial deposition patterns of lignin and polysaccharides in Arabidopsis, doubling the sugar yields after mild pre-treatment and enzymatic hydrolysis without affecting plant growth (Yang et al., 2012).

Knowledge of the TFs involved in SCW formation can also be exploited for breeding of cultivars with improved cell wall characteristics. Several QTLs for lignin- and saccharification-related traits in maize and sorghum have been shown to co-localize with TFs that regulate SCW biosynthesis (Barriere et al., 2012; Wang et al., 2013), providing inroads for improving desired SCW traits related to forage feeding value and saccharification yield through marker-assisted breeding.

In summary, Cassan-Wang et al. (2013) have highlighted an effective approach for identifying novel TFs involved in Arabidopsis SCW formation, providing a solid platform for more detailed functional analysis. The emerging picture is that of an increasingly complex regulatory network underlying SCW formation. Fitting together the pieces of the transcriptional puzzle will be challenging but the process will provide us with essential knowledge and tools to re-program and improve cell wall related traits.

\section{ACKNOWLEDGMENTS}

The authors would like to acknowledge funding for Rakesh Bhatia from the
Biotechnology and Biological Sciences Research Council (BBSRC) in the form of an Integrated Biorefining Research and Technology Club (IBTI) studentship $(\mathrm{BB} / \mathrm{K} 500926 / 1)$. Maurice Bosch is funded by the BBSRC Institute Strategic Programme Grant on Energy Grasses \& Biorefining (BB/J0042/1).

\section{REFERENCES}

Ambavaram, M. M. R., Krishnan, A., Trijatmiko, K. R., and Pereira, A. (2011). Coordinated activation of cellulose and repression of lignin biosynthesis pathways in rice. Plant Physiol. 155, 916-931. doi: 10.1104/pp.110.168641

Barriere, Y., Mechin, V., Lefevre, B., and Maltese, S. (2012). QTLs for agronomic and cell wall traits in a maize RIL progeny derived from a cross between an old Minnesota13 line and a modern Iodent line. Theor. Appl. Genet. 125, 531-549. doi: 10.1007/s00122-012-1851-5

Bosch, M., Mayer, C.-D., Cookson, A., and Donnison, I. S. (2011). Identification of genes involved in cell wall biogenesis in grasses by differential gene expression profiling of elongating and non-elongating maize internodes. J. Exp. Bot. 62, 3545-3561. doi: 10.1093/jxb/err045

Cassan-Wang, H., Goué, N., Saidi, M. N., Legay, S., Sivadon, P., Goffner, D., et al. (2013). Identification of novel transcription factors regulating secondary cell wall formation in Arabidopsis. Front. Plant Sci. 4:189. doi: 10.3389/fpls.2013.00189

Demartini, J. D., Pattathil, S., Miller, J. S., Li, H., Hahn, M. G., and Wyman, C. E. (2013). Investigating plant cell wall components that affect biomass recalcitrance in poplar and switchgrass. Energy Environ. Sci. 6, 898-909. doi: 10.1039/C3EE23801F

Handakumbura, P. P., and Hazen, S. P. (2012). Transcriptional regulation of grass secondary cell wall biosynthesis: playing catch-up with Arabidopsis thaliana. Front. Plant Sci. 3:74. doi: 10.3389/fpls.2012.00074

Himmel, M. E., Ding, S. Y., Johnson, D. K., Adney, W. S., Nimlos, M. R., Brady, J. W., et al. (2007). Biomass recalcitrance: engineering plants and enzymes for biofuels production. Science 315, 804-807. doi: 10.1126/science.1137016

Hirano, K., Aya, K., Morinaka, Y., Nagamatsu, S., Sato, Y., Antonio, B. A., et al. (2013). Survey of genes involved in rice secondary cell wall formation through a co-expression network. Plant Cell Physiol. 54, 1803-1821. doi: 10.1093/pcp/ pct 121

Hiratsu, K., Matsui, K., Koyama, T., and OhmeTakagi, M. (2003). Dominant repression of target genes by chimeric repressors that include the EAR motif, a repression domain, in Arabidopsis. Plant J. 34, 733-739. doi: 10.1046/j.1365-313X.2003.01759.x

Hussey, S. G., Mizrachi, E., Creux, N. M., and Myburg, A. A. (2013). Navigating the transcriptional roadmap regulating plant secondary cell wall deposition. Front. Plant Sci. 4:325. doi: 10.3389/fpls.2013.00325

McCarthy, R. L., Zhong, R., and Ye, Z.-H. (2009). MYB83 is a direct target of SND1 and acts redundantly with MYB46 in the regulation of secondary 
cell wall biosynthesis in Arabidopsis. Plant Cell Physiol. 50, 1950-1964. doi: 10.1093/pcp/pcp139

Melzer, S., Lens, F., Gennen, J., Vanneste, S., Rohde, A., and Beeckman, T. (2008). Flowering-time genes modulate meristem determinacy and growth form in Arabidopsis thaliana. Nat. Genet. 40, 1489-1492. doi: 10.1038/ng.253

Öhman, D., Demedts, B., Kumar, M., Gerber, L., Gorzsás, A., Goeminne, G., et al. (2013). MYB103 is required for FERULATE-5-HYDROXYLASE expression and syringyl lignin biosynthesis in Arabidopsis stems. Plant J. 73, 63-76. doi: 10.1111/tpj.12018

Ruprecht, C., Mutwil, M., Saxe, F., Eder, M., Nikoloski, Z., and Persson, S. (2011). Large-scale co-expression approach to dissect secondary cell wall formation across plant species. Front. Plant Sci. 2:23. doi: 10.3389/fpls.2011.00023

Sarkar, P., Bosneaga, E., and Auer, M. (2009). Plant cell walls throughout evolution: towards a molecular understanding of their design principles. J. Exp. Bot. 60, 3615-3635. doi: 10.1093/jxb/erp245

Shen, H., Poovaiah, C. R., Ziebell, A., Tschaplinski, T. J., Pattathil, S., Gjersing, E., et al. (2013). Enhanced characteristics of genetically modified switchgrass (Panicum virgatum L.) for high biofuel production. Biotechnol. Biofuels 6:71. doi: 10.1186/17546834-6-71

Sibout, R., Plantegenet, S., and Hardtke, C. S. (2008). Flowering as a condition for xylem expansion in Arabidopsis hypocotyl and root. Curr. Biol. 18, 458-463. doi: 10.1016/j.cub.2008.02.070
Vahala, J., Felten, J., Love, J., Gorzsás, A., Gerber, L., Lamminmäki, A., et al. (2013). A genome-wide screen for ethylene-induced ethylene response factors (ERFs) in hybrid aspen stem identifies ERF genes that modify stem growth and wood properties. New Phytol. 200, 511-522. doi: $10.1111 /$ nph. 12386

Vogel, J. (2008). Unique aspects of the grass cell wall. Curr. Opin. Plant Biol. 11, 301-307. doi: 10.1016/j.pbi.2008.03.002

Wang, Y. H., Acharya, A., Burrell, A. M., Klein, R. R., Klein, P. E., and Hasenstein, K. H. (2013). Mapping and candidate genes associated with saccharification yield in sorghum. Genome 56, 659-665. doi: 10.1139/gen-2013-0134

Xu, B., Sathitsuksanoh, N., Tang, Y., Udvardi, M. K., Zhang, J.-Y., Shen, Z., et al. (2012). Overexpression of AtLOV1 in switchgrass alters plant architecture, lignin content, and flowering Time. PLoS ONE 7:e47399. doi: 10.1371/journal.pone.0047399

Yang, F., Mitra, P., Zhang, L., Prak, L., Verhertbruggen, Y., Kim, J.-S., et al. (2012). Engineering secondary cell wall deposition in plants. Plant Biotechnol. J. 11, 325-335. doi: 10.1111/pbi.12016

Zhao, Q., Wang, H., Yin, Y., Xu, Y., Chen, F., and Dixon, R. A. (2010). Syringyl lignin biosynthesis is directly regulated by a secondary cell wall master switch. Proc. Natl. Acad. Sci. U.S.A. 107, 14496-14501. doi: 10.1073/pnas.1009170107

Zhong, R., Richardson, E. A., and Ye, Z. H. (2007). The MYB46 transcription factor is a direct target of SND1 and regulates secondary wall biosynthesis in Arabidopsis. Plant Cell 19, 2776-2792. doi: 10.1105/tpc.107.053678

Zhong, R. Q., Lee, C., McCarthy, R. L., Reeves, C. K., Jones, E. G., and Ye, Z. H. (2011). Transcriptional activation of secondary wall biosynthesis by rice and maize NAC and MYB transcription factors. Plant Cell Physiol. 52, 1856-1871. doi: $10.1093 / \mathrm{pcp} / \mathrm{pcr} 123$

Conflict of Interest Statement: The authors declare that the research was conducted in the absence of any commercial or financial relationships that could be construed as a potential conflict of interest.

Received: 26 March 2014; paper pending published: 09 April 2014; accepted: 23 April 2014; published online: 14 May 2014.

Citation: Bhatia R and Bosch M (2014) Transcriptional regulators of Arabidopsis secondary cell wall formation: tools to re-program and improve cell wall traits. Front. Plant Sci. 5:192. doi: 10.3389/fpls.2014.00192

This article was submitted to the journal Frontiers in Plant Science.

Copyright (c) 2014 Bhatia and Bosch. This is an openaccess article distributed under the terms of the Creative Commons Attribution License (CC BY). The use, distribution or reproduction in other forums is permitted, provided the original author(s) or licensor are credited and that the original publication in this journal is cited, in accordance with accepted academic practice. No use, distribution or reproduction is permitted which does not comply with these terms. 